\title{
Peak mooring forces in the horizontal interlaced multi-layered moored floating pipe breakwater
}

\author{
Vishwanath Mane, Sacchi Rajappa, Subba Rao and Vittal Hegde A
}

\author{
Department of Applied Mechanics and Hydraulics, National Institute of Technology Karnataka, India
}

\begin{abstract}
Present study aims to investigate the influence of relative breakwater width $W / L$ ( $W=$ width of breakwater, $L=$ wavelength), wave steepness $H_{i} / g T^{2}\left(H_{i}=\right.$ incident wave height, $T=$ wave period) and relative wave height $d / W(d=$ water depth) on forces in the moorings of horizontal interlaced multi-layered moored floating pipe breakwater (HIMMFPB) model. Studies were conducted on scaled down physical models having three layers of Poly Vinyl Chloride (PVC) pipes, wave steepness $H_{i} / g T^{2}$ varying from 0.063 to 0.849 , relative width $W / L$ varying from 0.4 to 2.65 and relative spacing $S / D=2$ ( $S=$ horizontal centre-to-centre spacing of pipes, $D=$ diameter of pipes). Peak mooring forces were also measured and data collected is analyzed by plotting non-dimensional graphs depicting variation of $f_{s} / \gamma W^{2}\left(f_{s}=\right.$ Sea side Mooring force, $\gamma=$ specific weight of water) \& $f_{l} / \gamma W^{2}$ (f $f_{l}=$ Lee side Mooring force) with $H_{i} / g T^{2}$ for $d / W$ varying from 0.082 to 0.276 and also variation of $f_{s} / \gamma W^{2}$ and $f_{l} / \gamma W^{2}$ with $W / L$ for $H_{i} / d$ varying from 0.06 to 0.400 .
\end{abstract}

KEY WORDS: Mooring forces; Wave steepness; Relative breakwater width; Ratio of spacing to diameter of pipes; Relative wave height.

\section{NOTATIONS}

The following symbols are used in this paper:

$$
\begin{array}{ll}
d & =\text { depth of water } \\
D & =\text { diameter of PVC pipes } \\
f & =\text { Peak force in the moorings } \\
f_{s} & \text { = Sea side peak mooring force } \\
f_{l} & \text { = Lee side peak mooring force } \\
g & =\text { acceleration due to gravity; } \\
H_{i} & =\text { incident wave height; } \\
L & =\text { wavelength; } \\
S & =\text { spacing of pipes; } \\
T & =\text { wave period; and } \\
W & =\text { Width of breakwater }
\end{array}
$$

\section{INTRODUCTION}

The environmental stress on the coastal zone is rapidly growing and there is a need to protect the coastal environment. The development of structures to provide protection against the destructive forces of the sea waves and

Corresponding author: Vittal Hegde A

e-mail:arkalvittal@gmail.com to withstand the action of waves has been the constant challenge to the coastal engineers. Current environmental and financial restrictions on the marina developments dictate that alternatives to traditional fixed rubble mound and caisson breakwater are required. The most common solution is the floating type breakwater.

Floating breakwaters are less expensive compared to conventional type breakwaters which are founded on the ocean bed. They can be used as temporary protection for offshore activities in hostile environment during construction, drilling works, salvage operations etc. Concept of Floating breakwaters is conceived based on reflection of wave energy or dissipation of wave energy by induced turbulent motion. The prime factor in the construction of the floating breakwaters is to make the width of the breakwater in the direction of wave propagation greater than one-half the wavelength and preferably as wide as the incident wavelength; else, the breakwater rides over the top of the wave without attenuating it. Also to be effective, the floating breakwater must be moored in place with both leeward and windward ties; otherwise, it would sag off and ride over the incident wave. Moorings, whether constructed of piles or mooring lines and anchors, must hold the breakwater in place and a careful assessment of mooring forces during the design storm wave attack must be made, to ensure the survival of the breakwater.

The development of floating breakwaters by various investigators has been influenced by several important 
features: large masses, large moment of inertia, and the combinations of two or more of the concepts of large effective mass or moment of inertia. Most of the literature indicates that the parameter "relative width" greatly influences the wave attenuation characteristics of the breakwater.

\section{LITERATURE REVIEW}

Harris and Webber (1968) carried out a series of tests on floating breakwater models to measure wave attenuation and mooring forces. It was concluded that the mooring forces were at their maximum for wavelength/solid breadth ratio between 1.0 and 2.0, whereas, if the ratio is beyond 2.0, the forces diminished abruptly. Brebner and Ofuya (1968) conducted studies on an " $\mathrm{A}$ " frame and concluded that the peak mooring forces were about 1.5-2 times the average mooring forces. Harms (1979) presented design curves for the Goodyear floating tire breakwater based on the laboratory tests, and additionally substantiated by available full scale data. Two important floating tire breakwater design parameters have been assessed over a practical range of conditions, i.e. the breakwater size required for a desired level of wave attenuation and the associated peak mooring force.

Mani (1991) concluded that in order to achieve a transmission coefficient of less than 0.5 , the relative width has to be around 0.15 . The studies also revealed that for small values of wave parameter $H_{i} / g T^{2}(0.0025)$, the Y-frame floating breakwater predicted a $13.5 \%$ increase in the mooring force compared to twin pontoon floating breakwater and for $H_{i} / g T^{2}$ values between 0.0025 and 0.012 , the Y-frame floating breakwater predicted an increase in mooring forces.

Murali and Mani (1997) studied conventional floating breakwaters and the feasibility of developing a cage floating breakwater was explored. It was concluded that though the stiffness of mooring lines did not modify the hydrodynamic performance characteristics of the breakwater, use of mooring lines with adequate stiffness is essential. Sannasiraj et al. (1998) based on the experimental and theoretical investigations on the behavior of pontoon type floating breakwaters concluded that theoretical and experimental measurements showed good agreement. The moorings at the water surface and at the bottom of the floating breakwater yielded significantly smaller mooring forces than those obtained with crossed mooring.

Sundar et al. (2003) studied the hydrodynamic performance characteristics of a floating pipe breakwater model (row of pipes separated by a distance equivalent to the pipe diameter) moored to the flume floor with a slack mooring. The reflection and transmission coefficients were evaluated as a function of relative breakwater width $W / L$. The mooring forces decreased with increase in $W / L$ above 0.6 .

Hegde et al. (2008) studied the transmission characteristics of horizontal interlaced multilayer moored FPBW model with three layers of PVC pipes and relative spacing of 5 . The normalized force increases with an increase in $H_{i} / L$, and decreases with an increase in $W / L$. The normalized force shows an increasing trend beyond a W/L value of 1.3. The forces in the moorings are more in breakwater with relative spacing of 2 than that with relative spacing of 4. Influence of $H_{i} / d$ is significant on the normalized force. The maximum measured peak force on seaward side mooring of the model with relative spacing of 2 was $80.44 \mathrm{~N}$ and that with relative spacing of 4 was $60.82 \mathrm{~N}$, corresponding to values of $H_{i} / L$ of $0.0397, H_{i} / d$ of 0.36 , and $W / L$ of 1.2. This indicates that peak mooring forces with relative spacing of 2 is more than that with relative spacing of 4. The peak forces in both the moorings (seaward side and leeward side) were maximum corresponding to values of $H_{i} / L$ of $0.0397, H_{i} / d$ of 0.36 , and $W / L$ of 1.2. The seaward side peak mooring forces were found to be always higher than the corresponding leeward side peak mooring forces. Maximum wave attenuation by breakwater model with relative spacing of 2 was $51.7 \%$ and that by breakwater model with relative spacing of 4 was $55.7 \%$.

The literature survey carried out clearly indicates that the studies on peak forces in the mooring forces of horizontal interlaced moored floating pipe breakwater $(n=3, S / d=2)$ model has not been carried out. Hence, The present paper deals with the investigation of peak forces in the seaward side and leeward side mooring lines of this type of breakwater (HIMMFPB) models in the regular wave flume of the department of Applied Mechanics and Hydraulics of National Institute of Technology Karnataka (NITK), Surathkal, Mangalore, Karnataka, India.

\section{DIMENSIONAL ANALYSIS}

The dimensional analysis is carried out using Buckingham's $\pi$ theorem. The variables considered under the present investigations are: $W$, width of the breakwater; $d$, depth of water; $L$, wavelength; $H_{i}$, incident wave height; $H_{t}$, transmitted wave height; $T$, wave period; $F$, peak forces in moorings; $\rho$, mass density of water; $g$, acceleration due to gravity. Considering $L, H_{i}$, and $\rho$ as repeating variables, dimensional analysis yields following non-dimensional $\pi$ terms: $W / L, H_{i} / g T^{2}, d / W$ and $H_{i} / d$.

\section{EXPERIMENTAL INVESTIGATIONS}

The present experimental studies were carried out in the regular wave flume of size $50 \mathrm{~m} \times 0.74 \mathrm{~m} \times 1.1 \mathrm{~m}$ available at the Department of Applied Mechanics and Hydraulics, National Institute of Technology Karnataka, Surathkal, Mangalore, India. Regular waves were generated in a chamber of dimensions $6.3 \mathrm{~m} \times 1.5 \mathrm{~m} \times 1.4 \mathrm{~m}$ at one end of the flume using the bottom hinged flap. The flap is controlled by an induction motor of $11 \mathrm{~kW}$ and $1450 \mathrm{rpm}$. The motor is regulated by an inverter drive of $0-50 \mathrm{~Hz}$ rotating with the speed range of 0-1550 rpm. Regular waves of height $0.03 \mathrm{~m}$ to $0.24 \mathrm{~m}$, and periods of 0.8 to $4 \mathrm{~s}$ can be generated with this facility. Wave flume calibration was done before the 
experiments were conducted, by varying the eccentricity of the bar chain on the flywheel and frequency of the inverter. Details of the flume along with the positions of the breakwater model and the wave probes are presented in Fig. 1.
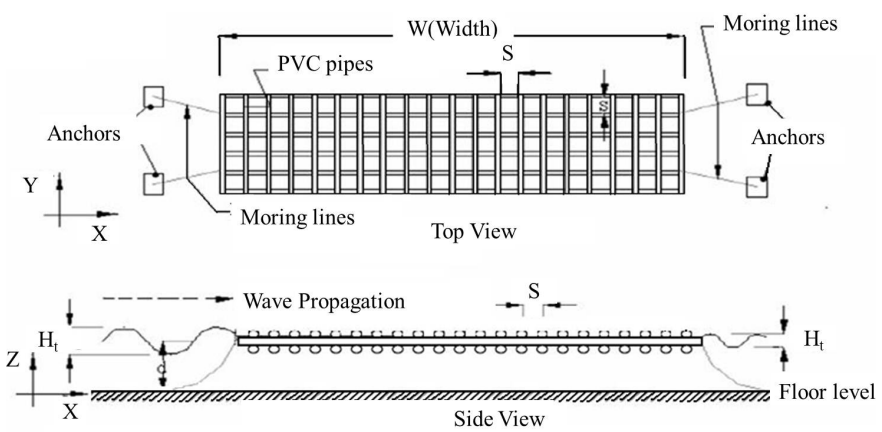

Fig. 1 Floating pipe breakwater model setup used in present work.

\section{BREAKWATER MODEL}

A pictorial representation of the breakwater model used in plan and section is shown in Fig. 1. The model consists of PVC pipes of $25 \mathrm{~mm}$ diameter. The pipes are placed parallel to each other with spacing $S$ between them in each layer, and the adjacent layers are oriented at right angles so as to form an interlacing of pipes. In the flume, longitudinal pipes are placed along the direction of propagation of waves and transverse pipes are placed and tied perpendicular to longitudinal pipes. Length of the longitudinal pipes defines the width $W$ of the floating breakwater. It is expected that with appropriate number of pipe layers $n$, spacing $S$, and relative breakwater width $W / L$, desired level of attenuation of incident waves may be achieved.

\section{INSTRUMENTATION}

In the present work, regular waves of different periods and heights as mentioned in Table 1 were generated for $W / L$ ratios of 0.4 to 2.65 . Based on the $W / L$ ratios used, the range of breakwater widths arrived were from $0.77 \mathrm{~m}$ to $5.45 \mathrm{~m}$. Waves were generated in bursts of 5 waves only, in order to avoid wave distortion due to reflection and rereflection from the breakwater structure and the wave paddle. After each burst wave generation was stopped till tranquility was achieved in the flume and thereafter next burst was generated. The breakwater model was placed in the flume at a distance of $28 \mathrm{~m}$ from the wave generator flap (Fig. 2).

Table 1 Details of the wave and structure-specific parameters considered in the present study.

\begin{tabular}{|c|c|}
\hline Wave-specific parameters & Experimental range \\
\hline Incident wave height, $H_{i}(\mathrm{~mm})$ & $\begin{array}{c}30,60,90,120 \\
150,180\end{array}$ \\
\hline Wave period, $T(s)$ & $\begin{array}{c}1.2,1.4,1.6,1.8 \\
2.0,2.2\end{array}$ \\
\hline Depth of water, $d(\mathrm{~mm})$ & $400,450,500$ \\
\hline Diameter of pipes, $D(\mathrm{~mm})$ & 25 \\
\hline $\begin{array}{l}\text { Ratio of spacing to diameter of } \\
\text { pipes, } S / D\end{array}$ & 2 \\
\hline Relative breakwater width, $W / L$ & 0.4 to 2.65 \\
\hline Number of layers, $n$ & 3 \\
\hline
\end{tabular}

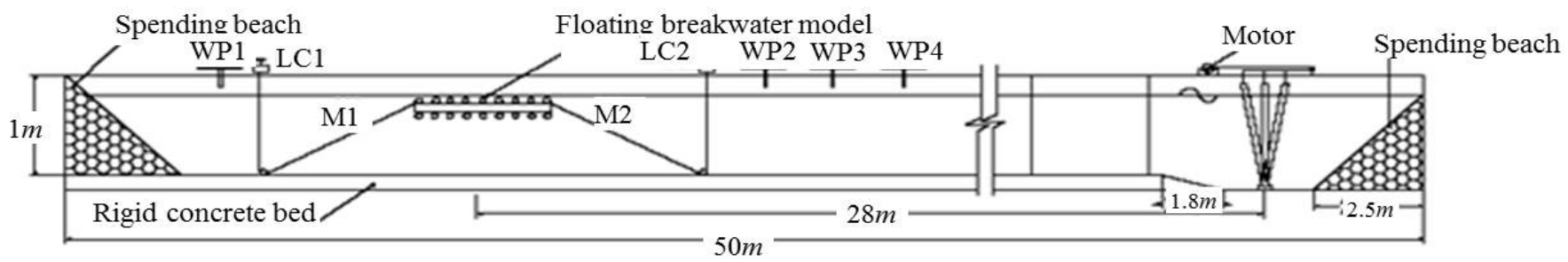

Sectional view

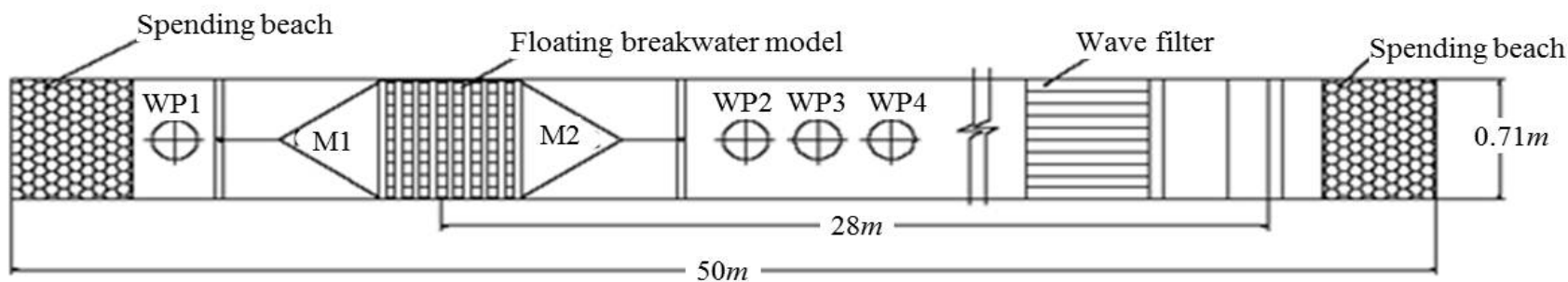

WP1 $=$ Wave probe on lee side WP2,WP3,WP4=Wave probe on sea side
PLAN

M1=Mooring line on lee side M2=Mooring line on sea side
$\mathrm{LC} 1=$ Load cell on lee side $\mathrm{LC} 2=$ Load cell on lee side

Fig. 2 Regular wave flume setup for the present investigations. 
Capacitance type wave probes were used to measure the incident and reflected wave heights. Probes were calibrated for every change in the model setup. Silica gel was applied to the probes at interval of 4 hours in order to reduce the surface tension. The superposed waves were measured by using three probes and the incident and reflected waves are decomposed from the superposed waves by using the 3 probes method proposed by Isaacson (1991). For a given particular depth, spacing between the probes is a function of wavelength $\mathrm{L}$, and probes are kept at equal intervals of $L / 3$ each.

The model scale used for breakwater was 1:30 for Arabian sea wave and site conditions. Wave periods used in the experiments varied from 1.2 to $2.2 \mathrm{~s}$ (A maximum prototype wave period of $12 \mathrm{sec}$ for Arabian sea conditions is considered) at an interval of $0.2 \mathrm{~s}$ and the corresponding wavelengths are calculated. For each wave period six different wave heights ranging from $0.03 \mathrm{~m}$ to $0.18 \mathrm{~m}$ (prototype maximum wave height of $5.4 \mathrm{~m}$ considered) at an interval of $0.03 \mathrm{~m}$ were generated. Water depths used varied from $0.40 \mathrm{~m}$ to $0.5 \mathrm{~m}$ at an interval of $0.05 \mathrm{~m}$ (A maximum prototype depth of $15 \mathrm{~m}$ is considered).

\section{RESULTS AND DISCUSSION}

Variation in the dimensionless peak mooring forces termed as 'peak sea side force parameter' and 'peak lee side force parameter' with $H_{i} / L$, and $d / W$ as parameter are shown in Figs. 3 to 16. The variation of peak force parameters with $\mathrm{W} / \mathrm{L}$, and $\mathrm{H}_{\mathrm{i}} / \mathrm{d}$ as parameter are shown in Figs. 17 to 24 . The graphs reveal that there is an increase in peak force parameter with increase in $H_{i} / L$ and decrease in peak force parameter with increase in $W / L$. This behavior is in agreement with the investigations carried out on floating breakwaters by Mani (1991) and Harms (1979).

\section{EFFECT OF WAVE STEEPNESS ON PEAK FORCE PARAMETER}

As the incident wave steepness increases the peak force parameter increases. This is because, an increase in wave height relative to wavelength causes high energy to impinge on the structure; hence there is an increase in peak force parameter.

\section{See side peak mooring force}

The variations of peak force parameter with wave steepness with $d / W$ as parameter are shown in Figs. 3 to 9 for the sea side peak mooring forces. There is an increase in peak force parameter with an increase in $H_{i} / g T^{2}$. An increase in wave height relative to wavelength causes high energy to impinge on the structure and hence there is an increase in peak force parameter. The graphs also indicate the influence of $d / W$ on peak force parameter.

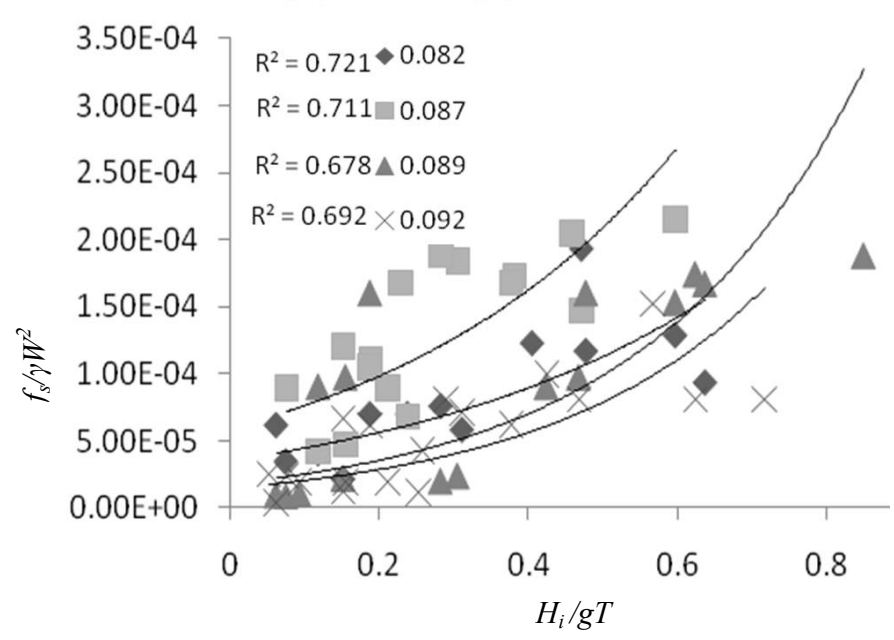

Fig. 3 Variation of $f_{s} / \gamma W^{2}$ with $H_{i} / g T^{2}$ for $n=3, S / D=2$ for $d / W$ $=0.082$ to 0.092 .

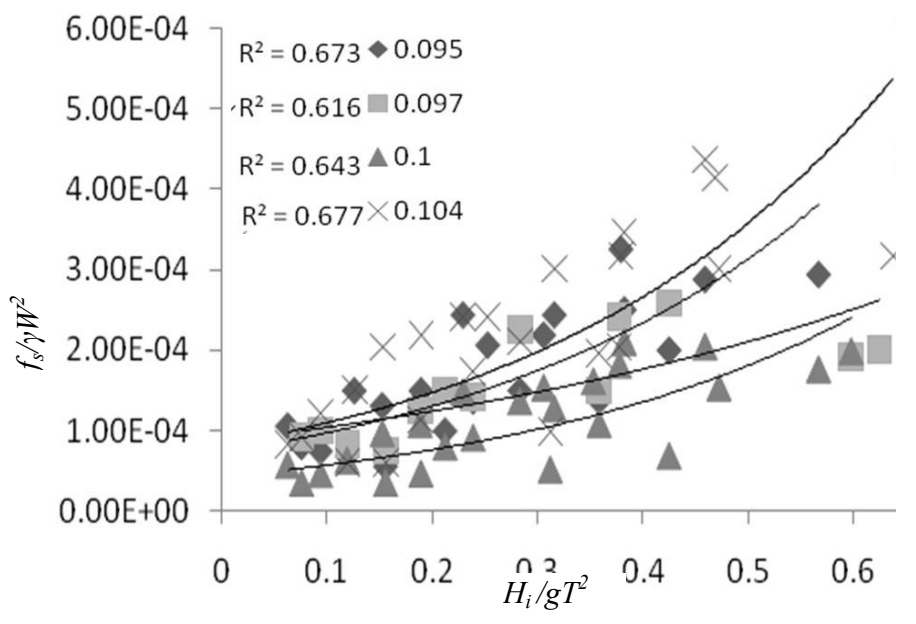

Fig. 4 Variation of $f_{s} / \gamma W^{2}$ with $H_{i} / g T^{2}$ for $n=3, S / D=2$ for $d / W$ $=0.092$ to 0.104 .

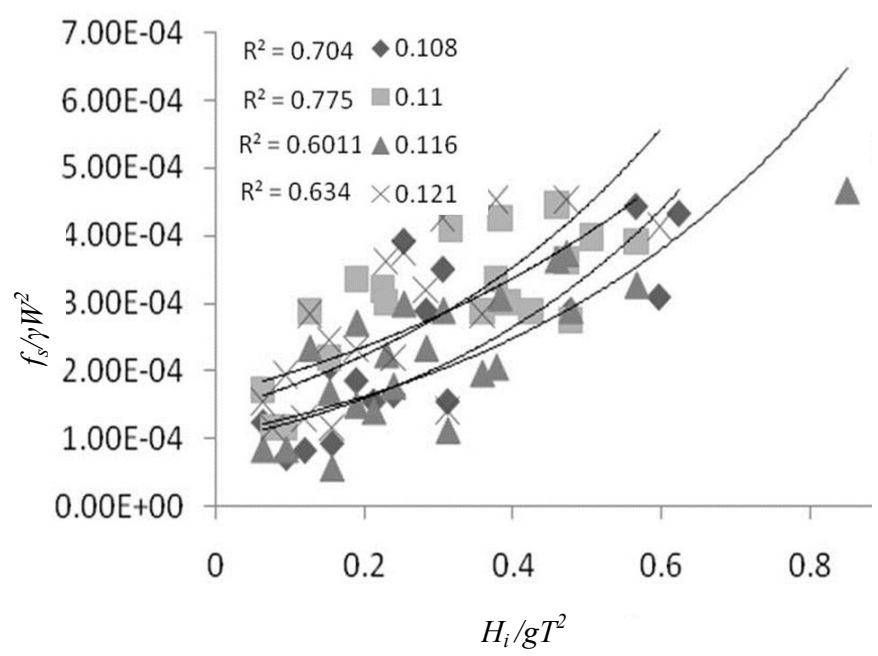

Fig. 5 Variation of $f_{s} / \gamma W^{2}$ with $H_{i} / g T^{2}$ for $n=3, S / D=2$ for $d / W$ $=0.108$ to 0.121 . 


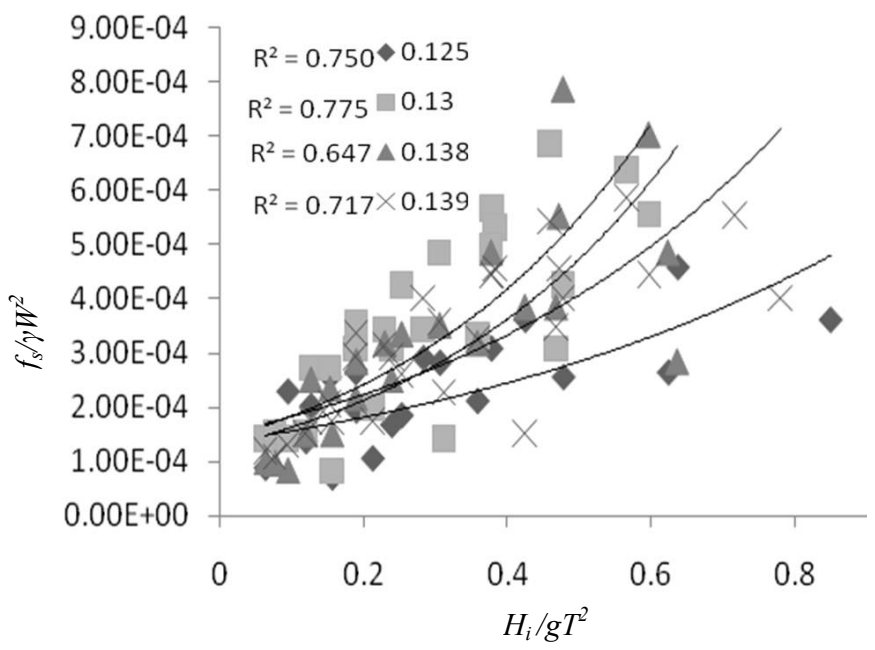

Fig. 6 Variation of $f_{s} / \gamma W^{2}$ with $H_{i} / g T^{2}$ for $n=3, S / D=2$ for $d / W$ $=0.125$ to 0.139 .

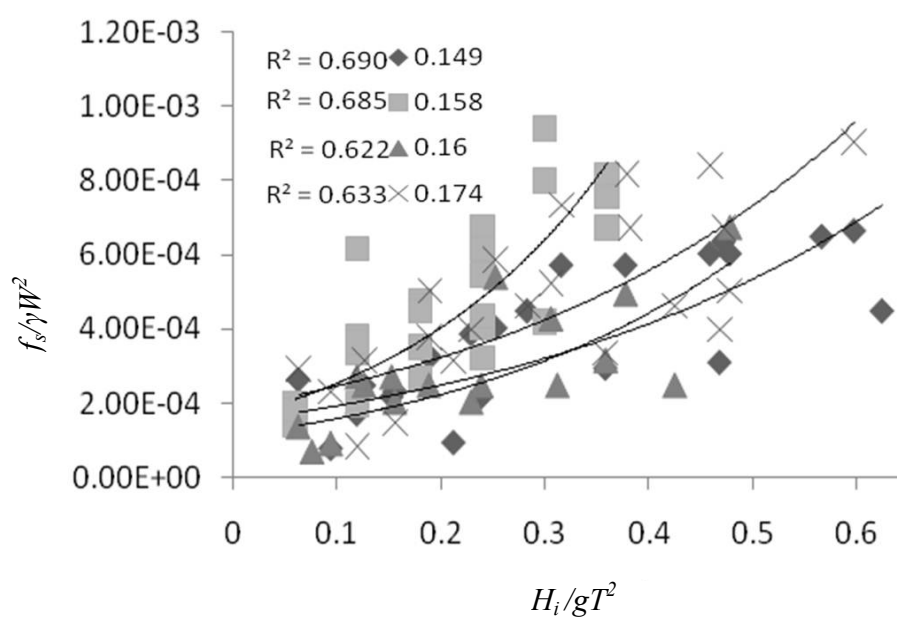

Fig. 7 Variation of $f_{s} / \gamma W^{2}$ with $H_{i} / g T^{2}$ for $n=3, S / D=2$ for $d / W$ $=0.149$ to 0.174 .

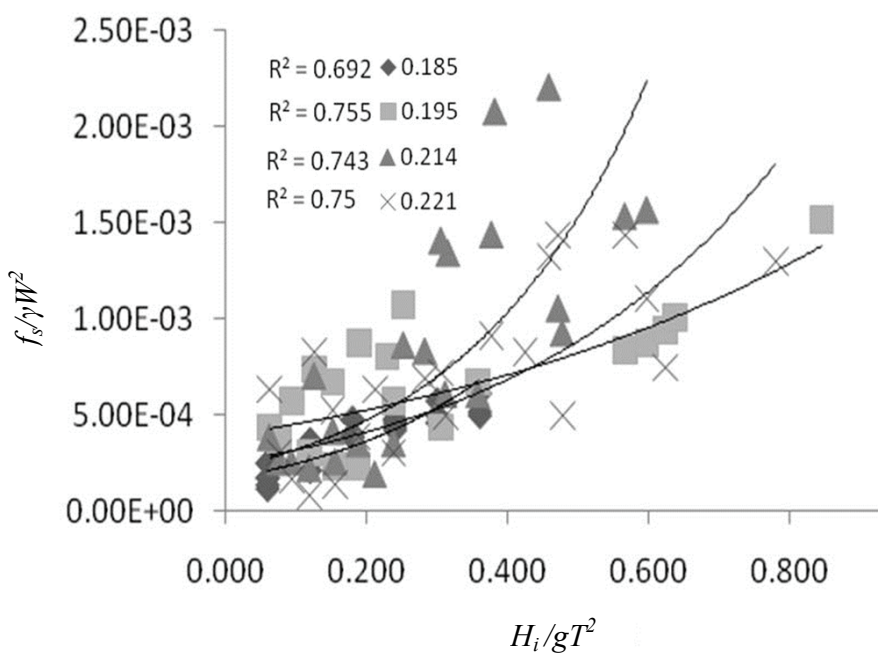

Fig. 8 Variation of $f_{s} / \gamma W^{2}$ with $H_{i} / g T^{2}$ for $n=3, S / D=2$ for $d / W$ $=0.185$ to 0.221 .

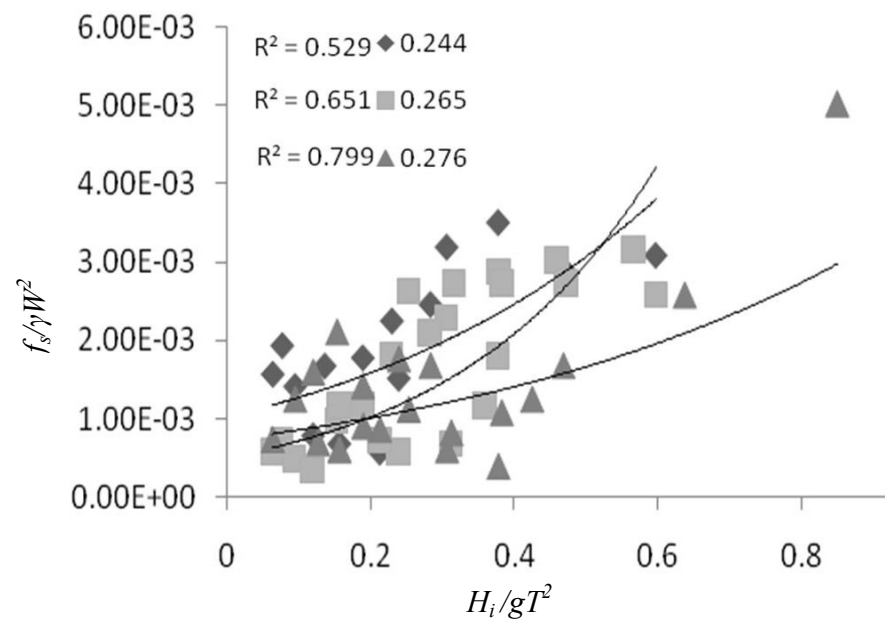

Fig. 9 Variation of $f_{s} / \gamma W^{2}$ with $H_{i} / g T^{2}$ for $n=3, \mathrm{i}=2$ for $d / W$ $=0.244$ to 0.276 .

The peak force parameter increases as $d / W$ increases. The probable reason for this behavior is as $W$ increases relative to $\mathrm{d}$, the breakwater width is such that the presence of both the crest and the trough of the wave on the breakwater leading to lower peak forces on the moorings.

Further, it is observed that for $d / W=0.082$ maximum peak force parameter attained was $2.06 \times 10^{-3}$ and for $d / W=$ 0.276 maximum peak force parameter was $5.46 \times 10^{-3}$. Hence, it clearly indicates the influence of $d / W$ on $f_{s} / \gamma W^{2}$

\section{Lee side peak mooring force}

The variations of force parameter with wave steepness with $d / W$ as parameter are shown in Figs. 10 to 16 for the lee side mooring forces. There is an increase in force parameter with an increase in $H_{i} / g T^{2}$. An increase in wave height relative to wavelength causes high energy to impinge on the structure hence; there is an increase in force parameter.

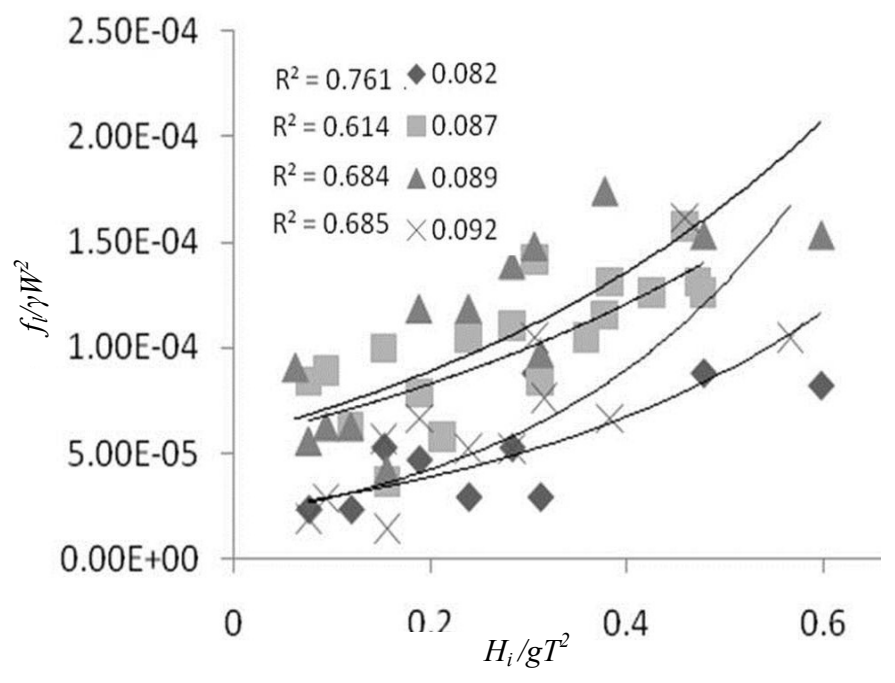

Fig. 10 Variation of $f_{l} / \gamma W^{2}$ with $H_{i} / g T^{2}$ for $n=3, S / D=2$ for $d / W$ $=0.082$ to 0.092 . 


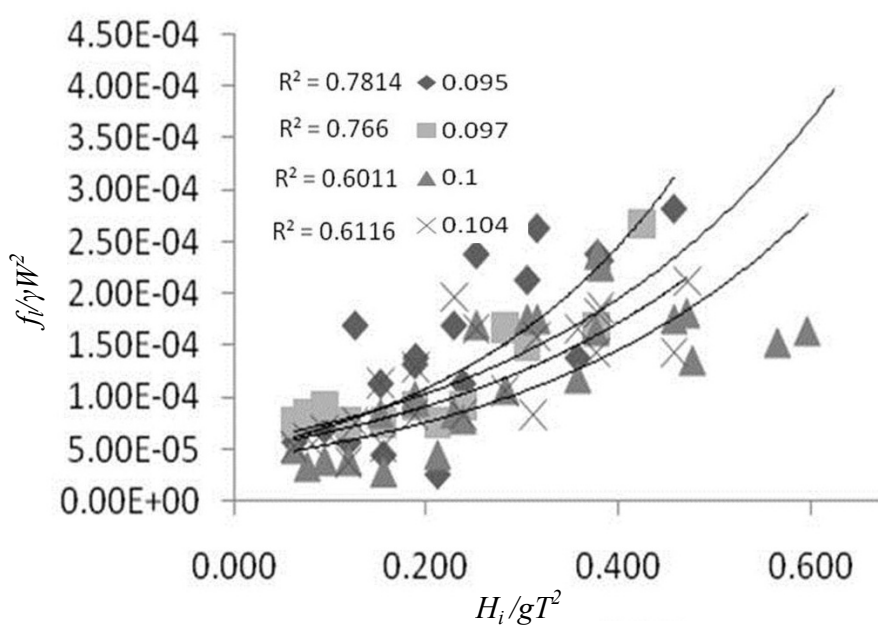

Fig. 11 Variation of $f_{l} / \gamma W^{2}$ with $H_{i} / g T^{2}$ for $n=3, S / D=2$ for $d / W$ $=0.095$ to 0.104 .

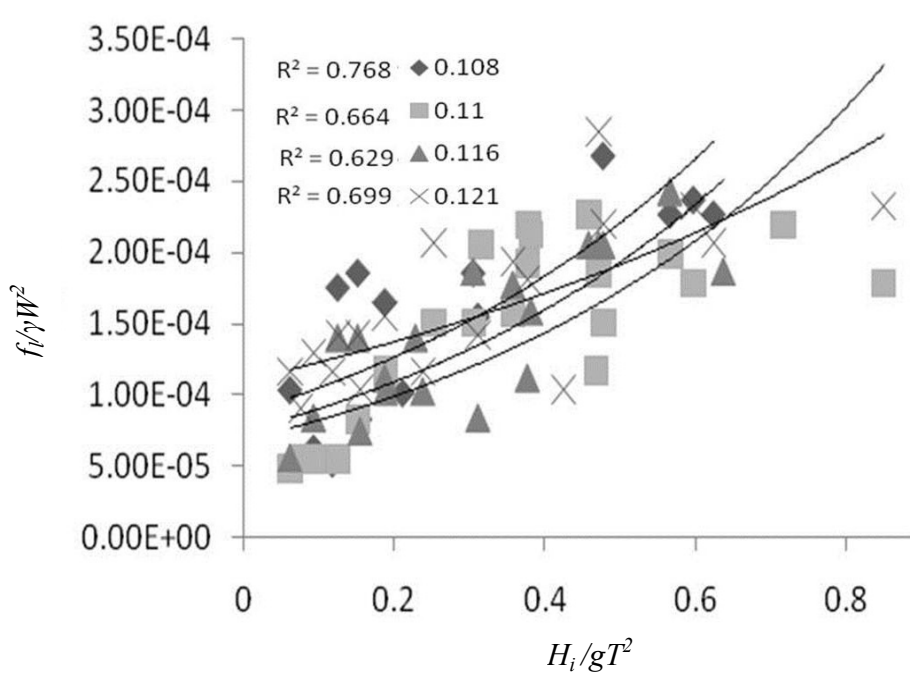

Fig. 12 Variation of $f_{l} / \gamma W^{2}$ with $H_{i} / g T^{2}$ for $n=3, S / D=2$ for $d / W$ $=0.108$ to 0.121 .

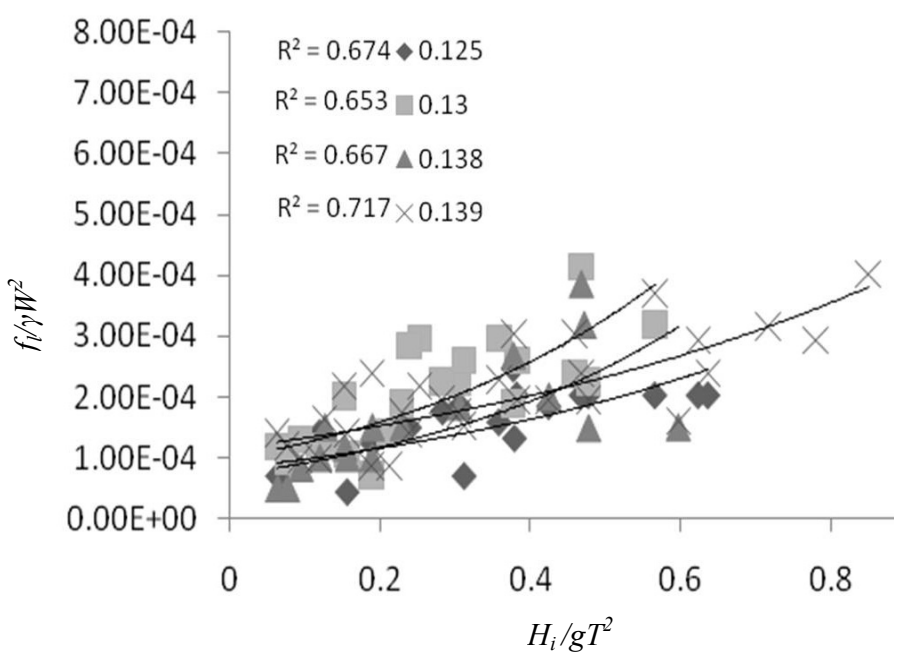

Fig. 13 Variation of $f_{l} / \gamma W^{2}$ with $H_{i} / g T^{2}$ for $n=3, S / D=2$ for $d / W$ $=0.125$ to 0.138 .

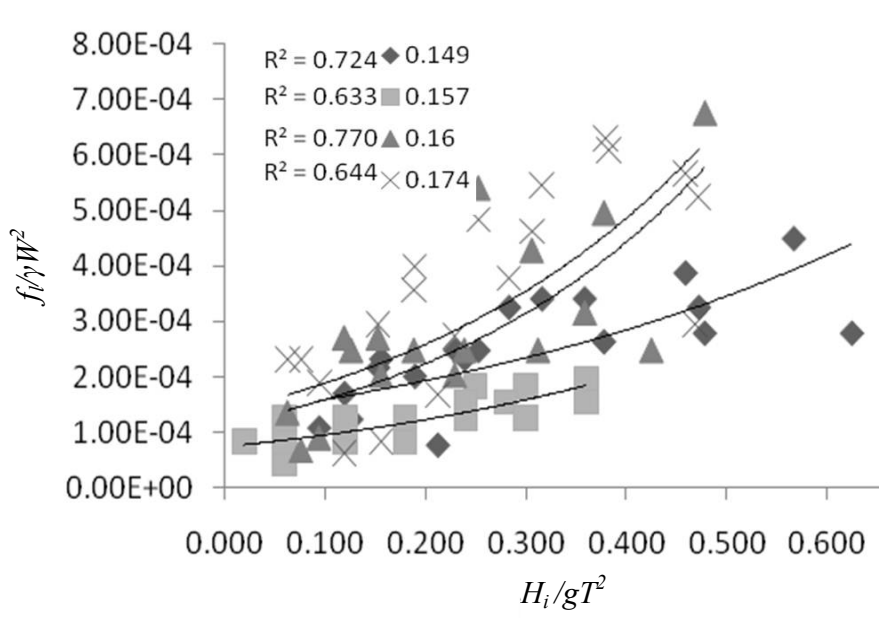

Fig. 14 Variation of $f_{l} / \gamma W^{2}$ with $H_{i} / g T^{2}$ for $n=3, S / D=2$ for $d / W$ $=0.149$ to 0.174 .

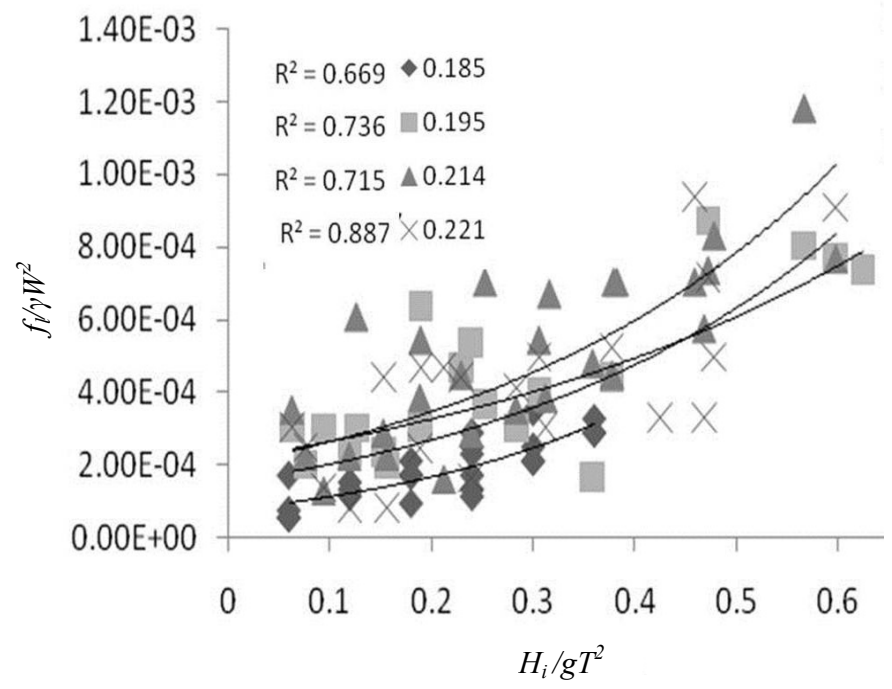

Fig. 15 Variation of $f_{l} / \gamma W^{2}$ with $H_{i} / g T^{2}$ for $n=3, S / D=2$ for $d / W$ $=0.185$ to 0.221 .

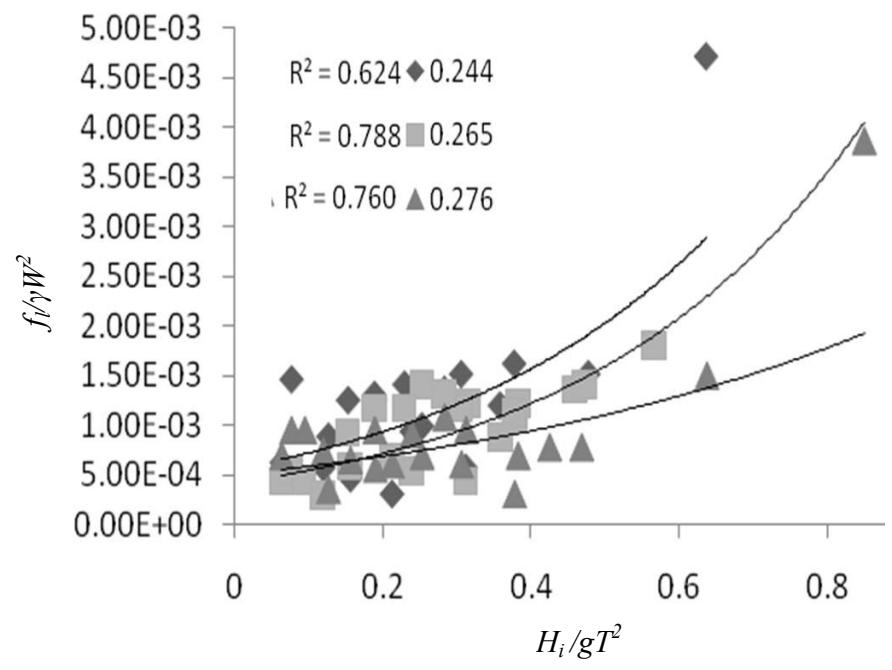

Fig. 16 Variation of $f_{l} / \gamma W^{2}$ with $H_{i} / g T^{2}$ for $n=3, S / D=2$ for $d / W$ $=0.224$ to 0.276 . 
The graphs also indicate the influence of $d / W$ on peak force parameter. The peak force parameter increases as $d / W$ increases.

The probable reason for this behavior is as $\mathrm{W}$ increases relative to $d$, the breakwater width is such that the presence of both the crest and the trough of the wave on the breakwater leading to lower peak forces on the moorings. Further, it is observed that for $d / W=0.082$ maximum peak force parameter attained was $1.46 \times 10^{-3}$ and for $d / W=0.276$ maximum peak force parameter was $1.17 \times 10^{-4}$. Hence, it clearly indicates the influence of $d / W$ on $f_{l} / \gamma W^{2}$.

\section{EFFECT OF RELATIVE BREAKWATER WIDTH ON PEAK FORCE PARAMETER}

\section{Sea side peak mooring force}

Relative width $(W / L)$ of the breakwater plays a significant role on peak force parameter, as the relative breakwater width increases the peak force parameter decreases. The wavelength is lower than the breakwater width leading to the presence of both crest and trough resulting in lower peak force in mooring lines.

Figs. 17 to 20 Show the variation of peak force parameter with relative breakwater width $(W / L)$ and $H_{i} / d$ as parameter for sea side peak mooring forces. The graphs show a decrease in peak force parameter with increase in $W / L$. The probable reason for this behavior is for low $W / L$, the wavelength is longer than the breakwater width leading to the presence of either the crest or the trough resulting in higher peak force in mooring lines.

As $W / L$ increases, the wavelength is shorter or equal to breakwater width leading to the presence of both crest and trough of the wave leading to decrease in peak forces in the moorings. The graphs also reveal that as $H_{i} / d$ increases an increase in the value of $f_{s} / \gamma W^{2}$ is observed.

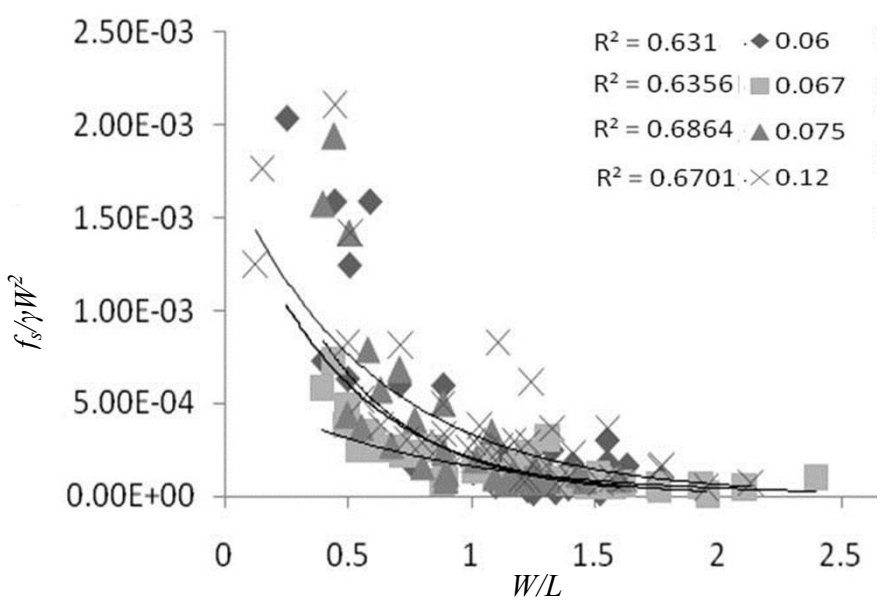

Fig. 17 Variation of $f_{s} / \gamma W^{2}$ with $W / L$ for $n=3, S / D=2$ for $H_{i} / d$ $=0.06$ to 0.12 .

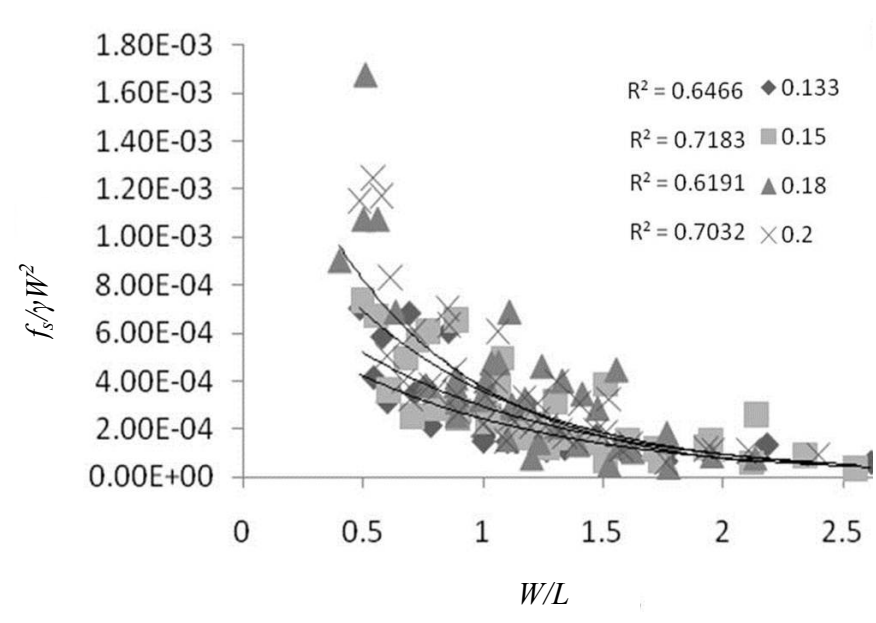

Fig. 18 Variation of $f_{s} / \gamma W^{2}$ with $W / L$ for $n=3, S / D=2$ for $H_{i} / d$ $=0.133$ to 0.2 .

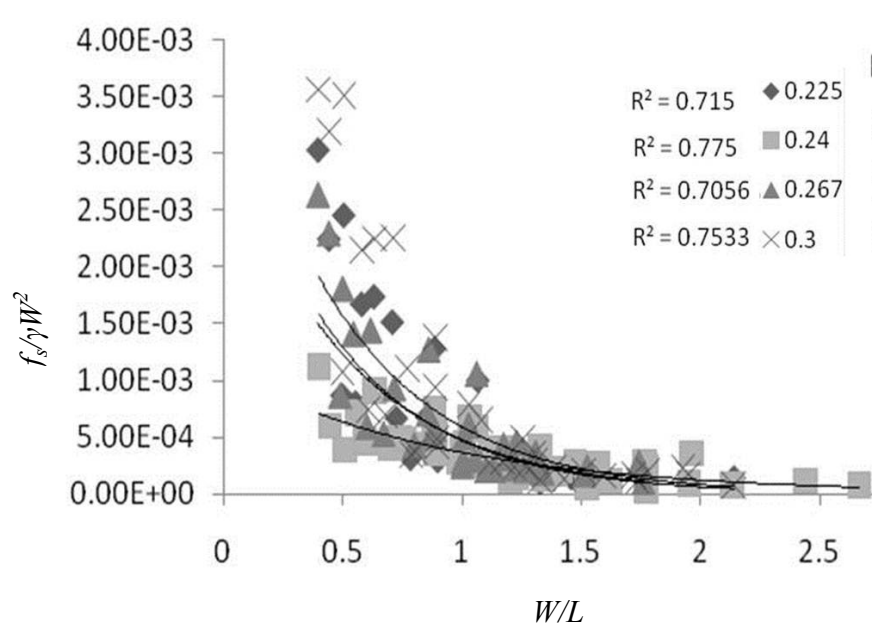

Fig. 19 Variation of $f_{s} / \gamma W^{2}$ with $W / L$ for $n=3, S / D=2$ for $H_{i} / d$ $=0.225$ to 0.30 .

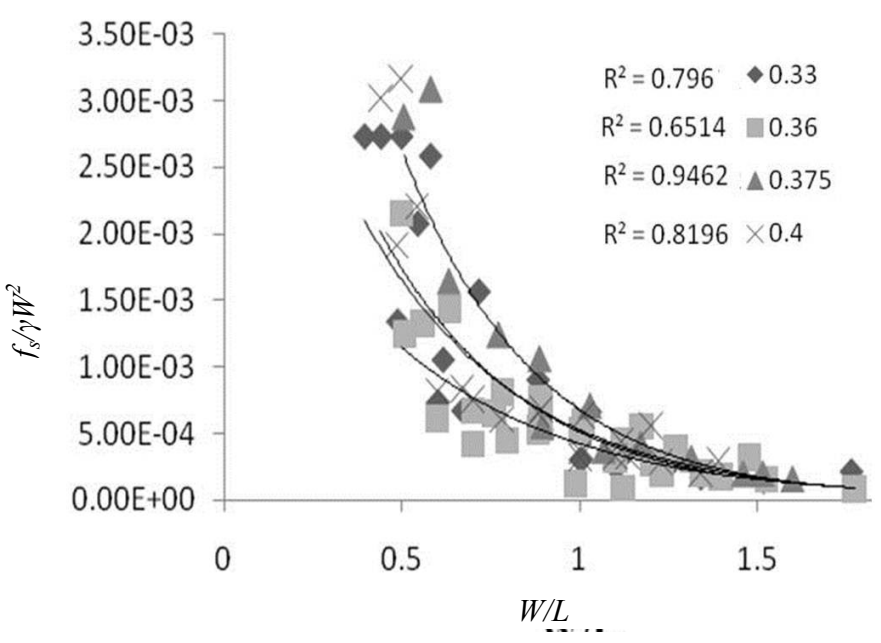

Fig. 20 Variation of $f_{s} / \gamma W^{2}$ with $W / L$ for $n=3, S / D=2$ for $H_{i} / d$ $=0.33$ to 0.40 . 
Further, it is observed that for $H_{i} / d=0.060$ maximum peak force parameter attained was $2.04 \times 10^{-3}$ and for $H_{i} / d=$ 0.40 maximum peak force parameter was $2.73 \times 10^{-3}$. Hence, it clearly indicates the influence of $H_{i} / d$ on $f_{s} / \gamma W^{2}$.

\section{Lee side peak mooring force}

Figs. 21 to 24 show the variation of peak force parameter with relative breakwater width $(W / L)$ and $H_{i} / d$ as parameter for lee side peak mooring forces.

The graphs show that decrease in peak force parameter with increase in $W / L$. The probable reason for this behavior is for low $W / L$, the wavelength is longer than the breakwater width leading to the presence of either the crest or the trough resulting in higher peak force in mooring lines. As $W / L$ increases, the wavelength is shorter or equal to breakwater width leading to the presence of both crest and trough of the wave leading to decrease in peak forces in the moorings..

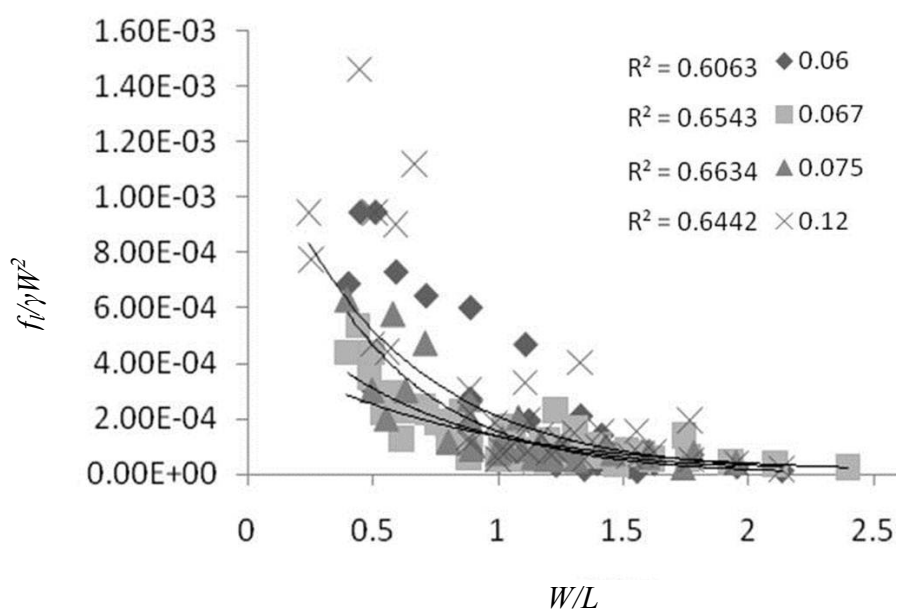

Fig. 21 Variation of $f_{l} / \gamma W^{2}$ with $W / \mathrm{L}$ for $n=3, S / D=2$ for $H_{i} / d$ $=0.063$ to 0.12 .

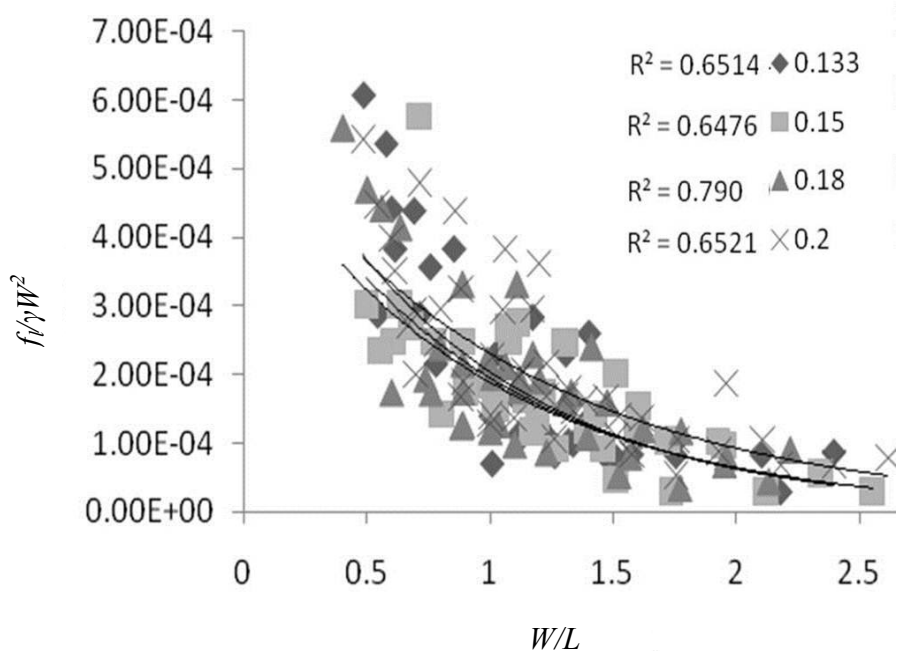

Fig. 22 Variation of $f_{l} / \gamma W^{2}$ with $W / L$ for $n=3, S / D=2$ for $H_{i} / d$ $=0.133$ to 0.20 .

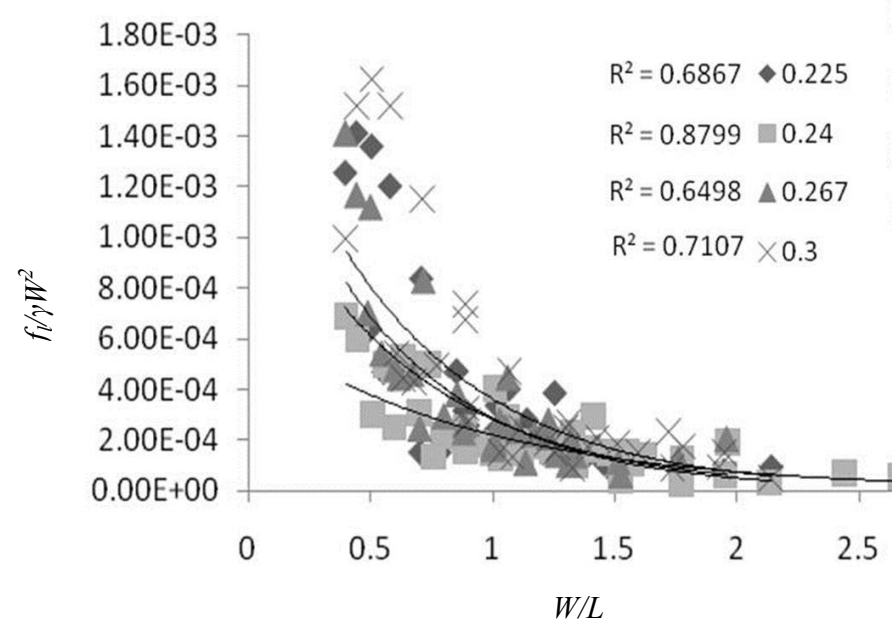

Fig. 23 Variation of $f_{l} / \gamma W^{2}$ with $W / L$ for $n=3, S / D=2$ for $H_{i} / d$ $=0.225$ to 0.30 .

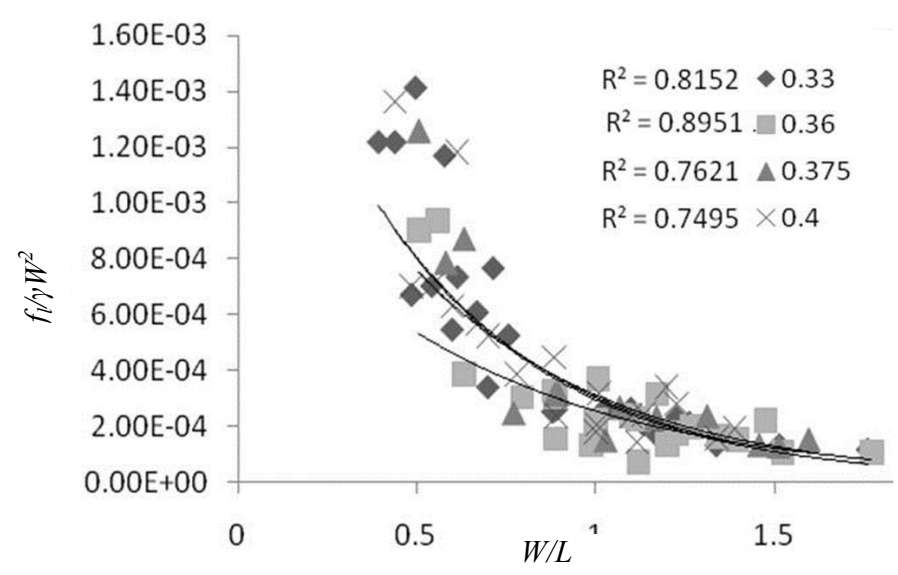

Fig. 24 Variation of $f_{l} / \gamma W^{2}$ with $W / L$ for $n=3, S / D=2$ for $H_{i} / d$ $=0.33$ to 0.40 .

The graphs also reveal that as $H_{i} / d$ increases an increase in the value of $f_{l} / \gamma W^{2}$ is observed. Further, it is observed that for $H_{i} / d=0.060$ maximum peak force parameter attained was $1.45 \times 10^{-3}$ and for $\mathrm{H}_{\mathrm{i}} / \mathrm{d}=0.400$ maximum peak force parameter was $1.56 \times 10^{-3}$. Hence, it clearly indicates the influence of $H_{i} / d$ on $f_{l} / \gamma W^{2}$

\section{CONCLUSIONS}

Based on the present investigations and results obtained following conclusions are drawn:

The normalized peak force increases with an increase in $H_{i} / g T^{2}$, and decreases with an increase in $W / L$. Influence of $H_{i} / d$ is significant on the normalized peak force. The maximum measured peak force on seaward side mooring of the model with relative spacing of 2 was $103.58 \mathrm{~N}$ corresponding to values of $H_{i} / g T^{2}$ of $0.420 H_{i} / d$ of 0.4 , and $W / L$ of 1.2 .

The peak forces in both the moorings (seaward side and leeward side) were maximum corresponding to values of $H_{i} / g T^{2}$ 
of $0.420 H_{i} / d$ of 0.4 , and $W / L$ of 1.2. The seaward side peak mooring forces were found to be always higher than the corresponding leeward side peak mooring forces. Maximum wave attenuation by breakwater model with relative spacing of 2 was $78 \%$.

\section{ACKNOWLEDGEMENTS}

The authors would like to express their sincere thanks to Director, National Institute of Technology Karnataka (NITK), Surathkal, Mangalore, India and also to the Head of Department of Applied Mechanics and Hydraulics, NITK for encouragement and providing all the necessary infrastructural facilities required for the present study.

\section{REFERENCES}

Brebner, A. and Ofuya, A.O., 1968. Floating Breakwaters. Proceedings of 11th Conference on Coastal Engineering, London, England, pp. 1055 - 1094.

Bishop, T.C., 1982. Floating tire breakwater design comparison, Journal of Waterway, Port, Coastal, and Ocean Engineering, ASCE, 108 (3), pp. 421-426.

Chen, K. and Wiegel, R.L., 1970. Floating breakwaters for reservoir marinas. Proceedings of the 12th Coastal Engineering Conference, Washington, DC, vol. III, pp. 1647-1666.
Harris, A.J. and Webber, N.B., 1968. A Floating breakwater. Proceedings of the 11th Coastal Engineering Conference, London, England, pp.10491054.

Harms, V.M., 1979. Design criteria for floating tire breakwater, Journal of Waterway, Port, Coastal, and Ocean Engineering, ASCE, 106 (2), pp.149-170.

Hegde, A.V. Kamath K. and Magadum A.S., 2008. Performance characteristics of horizontal interlaced multilayer moored floating pipe breakwater, Journal of Waterway, Port, Coastal, and Ocean Engineering, ASCE 133(4), pp. 275-285.

Mani, J.S. 1991. Design of Y-frame floating breakwater, Journal of Waterway, Port, Coastal, and Ocean Engineering, ASCE, 117 (2), pp. 105-119.

Michael Isaacson., 1991. Measurement of Regular Wave Reflection. Journal of Waterway, Port, and Ocean Engineering, 117(6), pp. 553-569.

Murali, K. and J.S. Mani., 1997. Performance of cage floating breakwater, Journal of Waterway, Port, Coastal, and Ocean Engineering, ASCE, 123(4), pp. 172-179.

Sannasiraj, S.A. Sundar, V. and Sundaravadivelu, R., 1998. Mooring forces and motion response of pontoon-type floating breakwaters. Ocean Engineering, 25(1), pp. $27-48$.

Sundar, V. Sundaravadivelu, R. and Purushotham, S., 2003. Hydrodynamic characteristics of moored floating pipe breakwater in random waves, Journal of Engineering for the Maritime Environment, 217(2), pp. $95-110$. 